\title{
Durasi Operasi yang Memanjang pada Pasien dengan Tumor Cerebellopontine Angle (CPA)
}

\author{
Harrison*), Kenanga M. Sikumbang ${ }^{* *)}$, Rapto Hardian***) \\ ${ }^{*}$ Residen Departemen Anestesiologi dan Terapi Intensif, Fakultas Kedokteran, Universitas Lambung Mangkurat/ \\ Rumah Sakit Ulin, Banjarmasin, ${ }^{* *}$ Divisi Neuroanesthesia, Departemen Anestesiologi dan Terapi Intensif, \\ Fakultas Kedokteran, Universitas Lambung Mangkurat/Rumah Sakit Ulin, Banjarmasin, ${ }^{* * *}$ Divisi Kardiovaskular \\ Departemen Anestesiologi dan Terapi Intensif, Fakultas Kedokteran, Universitas Lambung Mangkurat/Rumah \\ Sakit Ulin, Banjarmasin
}

\begin{abstract}
Abstrak
Tumor Cerebellopontine angle (CPA) merupakan tumor fossa posterior terbanyak dan merupakan 5-10\% dari tumor intrakranial. Penatalaksanaan anestesi pada kasus tumor CPA sangat menantang, dan memerlukan perhatian khusus terhadap disfungsi batang otak, posisi pasien, pemantauan neurofisiologi intraoperatif, dan adanya risiko venous air embolism (VAE). Pasien wanita, 16 tahun, $45 \mathrm{~kg}$, suspek CPA tipe schwannoma akustik dengan keluhan sakit kepala selama 2 bulan. Tidak ada riwayat tinitus dan gangguan keseimbangan. CT-scan kepala memperlihatkan massa padat dengan bagian kistik di cerebellopontine angle kanan. Prosedur pembedahan dilakukan dalam posisi prone dan memanjang hingga 13 jam. Rumatan anestesi ditujukan untuk stabilisasi hemodinamik dan pencegahan hipotermia dengan penghangat blower dan infus hangat. Perdarahan selama pembedahan sekitar $1800 \mathrm{ml}$. Pasien diekstubasi setelah 3 hari di ICU. Prosedur bedah untuk tumor CPA memiliki risiko tinggi dan membutuhkan waktu lama, sehingga meningkatkan mortalitas dan morbiditas akibat risiko hipotermia dan ketidakstabilan hemodinamik yang lebih tinggi. Pada kasus ini dengan keterbatasan alat monitoring, dilakukan observasi ketat untuk kejadian VAE dan pencegahan komplikasi pascabedah dengan menjaga hemodinamik tetap stabil dengan pemberian cairan adekuat dan pencegahan hipotermia dengan penggunaan blower warmer dan infus hangat. Pada kasus ini, lama pembedahan selama 13 jam diantisipasi dengan monitoring yang ketat, pemberian volume adekuat dan pencegahan hipotermi.
\end{abstract}

Kata kunci: Schwannoma akustik; pembedahan memanjang posisi prone; tumor CPA

JNI 2020; 9 (1): 45-50

\section{Prolonged Operation in Patient with Cerebellopontine Angle (CPA) Tumor}

\begin{abstract}
Cerebellopontine angle (CPA) tumor is the most common neoplasms in the posterior fossa, accounting for 5-10\% of intracranial tumors. Anesthetic management is very challenging and needs special attention due to brain dysfunction, patient position, neurophysiological monitoring intraoperative, and the risk of venous air embolism (VAE). Female patient, 16 years old, $45 \mathrm{~kg}$, with a suspected CPA acoustic schwannoma presented headache for 2 months. No history of tinnitus and balance disorders. Head CT-scan showed solid mass with cystic sections at right cerebellopontine angle. During procedure patient was in prone position and the operation took 13 hours long. Maintenance anesthesia aims to stabilize hemodynamic with adequate fluid replacement and prevention hypothermia with blower warmer and fluid warmer. Blood loss during the operation about $1800 \mathrm{ml}$. The patient was extubated after 3 days in the ICU. Surgical procedure in cerebellopontine angle surgery has a high risk and requires a long time. Prolonged duration of surgery will increases mortality and morbidity, because of the higher risk of hypothermia and hemodynamic instability. With limited monitoring equipment, we stabilize hemodynamic and to prevent the risk of VAE by adequate volume replacement. Hypothermia prevention by blower and fluid warmer. In this case, 13 hours long the operation makes us should maintenance hemodynamic by given adequate volume replacement and prevention of hypothermia.
\end{abstract}

Key words: Acoustic schwannoma; CPA tumor; prolonged surgery; prone position 


\section{Pendahuluan}

Cerebellopontine angle (CPA) merupakan suatu area berbentuk segitiga pada fossa posterior yang dibatasi oleh tulang temporal, serebelum dan pons. Pada daerah ini sering terdapat massa abnormal yang disebut sebagai tumor CPA, sering terjadi pada orang dewasa dengan jumlah berkisar 5-10\% dari seluruh tumor intrakranial. ${ }^{1}$ Sebagian besar tumor CPA bersifat jinak, dengan 80-94\% berupa schwannoma vestibular neuroma akustik, lipoma, malformasi vaskular, dan hemangioma. Tumor CPA non-akustik yang paling sering adalah meningioma (3-10\%), epidermoid/ kolesteatoma primer (2-4\%), dan schwannoma saraf kranial wajah. Keganasan primer atau lesi metastasis ditemukan kurang dari $2 \%{ }^{2}$

Tindakan bedah pada kasus tumor di fossa posterior memiliki kesulitan yang tinggi, dikarenakan ruang yang terbatas, banyaknya struktur saraf dan vascular, dan waktu operasi yang lama. Kondisi tersebut menjadi tantangan tersendiri bagi ahli bedah maupun ahli anestesi. Tantangan utama bagi ahli anestesi berupa risiko peningkatan tekanan intrakranial, posisi pasien, risiko disfungsi saraf kranial durante operasi, risiko tinggi terjadinya emboli udara pada pembuluh darah vena venous air embolism (VAE), dan kebutuhan penggunaan ventilasi mekanik pasca bedah. Pada operasi lama, lebih sering terjadi risiko terjadinya gangguan hemodinamik dan hipotermia. Kejadian hipotermia itu sendiri terjadi sebagai akibat dari berkurangnya ketersediaan oksigen di tingkat jaringan yang menyebabkan disfungsi trombosit melalui hambatan terhadap pusat pengatur suhu sehingga menghambat beberapa enzim yang terlibat dalam jalur intrinsik dan ekstrinsik dari kaskade koagulasi, dan menyebabkan pemanjangan protrombin dan parsial tromboplastin pada level kaskade koagulasi (ekstrinsik). ${ }^{3,4}$

Adapun, tujuan tindakan anestesi pada kasus bedah di fossa posterior yaitu memfasilitasi akses ke area bedah, meminimalisir risiko kerusakan jaringan saraf, dan mempertahankan stabilitas kardiorespirasi pasien. Oleh karena itu, diperlukan komunikasi yang baik antara ahli bedah dan ahli anestesi mengenai rencana pre-operatif, seperti pengaturan posisi pasien dan persiapan tindakan bedah. Pencegahan terjadinya VAE, dan pengetahuan mengenai gejala-gejala VAE, serta penatalaksanaan yang tepat merupakan hal yang sangat penting pada kasus tumor fossa posterior. ${ }^{5}$

\section{Kasus}

Seorang anak wanita 16 tahun, berat badan 45 $\mathrm{kg}$, dengan diagnosa cerebellopontin angle tumor suspek acoustic schwannoma masuk ke RSUD Ulin-Banjarmasinn dengan keluhan utama nyeri kepala yang hilang timbul sejak kurang lebih 2 bulan SMRS. Riwayat trauma, penurunan kesadaran, kejang, pendengaran berdengung dan gangguan keseimbangan disangkal. Kemudian, pasien dilakukan pemeriksaan CT-scan kepala dan dikonsulkan ke anestesi untuk penatalaksanaan perioperatif kraniotomi untuk pengangkatan tumor.

$\begin{array}{ll}\text { Pemeriksaan Fisik } & \\ \text { Kesadaran } & : \text { GCS 15: E4 M6 V5 } \\ \text { Tanda Vital } & : \text { Dalam batas normal } \\ \text { Paru dan Jantung } & : \text { Dalam batas normal } \\ \text { Ekstremitas atas } & : \text { motorik 5/5 } \\ \text { Ekstremitas bawah } & : \text { motorik 5/5 }\end{array}$

\section{Pemeriksaan Laboratorium}

\begin{tabular}{|c|c|}
\hline $\mathrm{Hb}$ & $: 10.6 \mathrm{gr} / \mathrm{dL}$ \\
\hline Hematokrit & $: \quad 37 \%$ \\
\hline Leukosit & : 9.400 \\
\hline Trombosit & $: 358.000$ \\
\hline PT & $: 11$ \\
\hline INR & $: 1.0$ \\
\hline aPTT & : 29.8 \\
\hline $\mathrm{Na}$ & $: \quad 139 \mathrm{mEq} / \mathrm{L}$ \\
\hline K & : $\quad 3.7 \mathrm{mEq} / \mathrm{L}$ \\
\hline SGOT & : 22 unit/L \\
\hline SGPT & : 25 unit/L \\
\hline Ureum & $13 \mathrm{mg} / \mathrm{dL}$ \\
\hline Kreatinin & $0,7 \mathrm{mg} / \mathrm{dL}$ \\
\hline $\begin{array}{l}\text { Glukosa Darah } \\
\text { Sewaktu }\end{array}$ & $83 \mathrm{mg} / \mathrm{dL}$ \\
\hline
\end{tabular}


Rontgen thorax: cor dan pulmo tidak ada kelainan. CT Scan kepala: tampak massa solid dengan bagian kistik ukuran $4,4 \times 4,1 \times 4,4 \mathrm{~cm}$ pada cerebellopontine angle kanan disertai pelebaran kanalis auditorius internus kanan yang menyebabkan hidrosefalus obstruktif, suspek acoustic schwanoma. (Gambar 1)

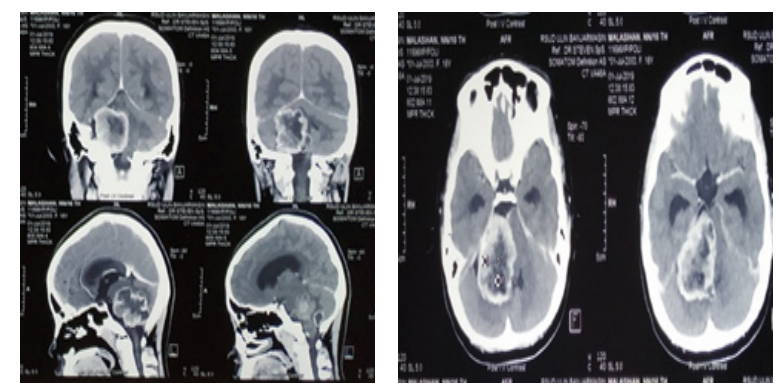

Gambar 1. CT-Scan Kepala

\section{Pengelolaan Anestesi}

Pasien dipuasakan dari makanan padat 6 jam sebelum operasi, minum air putih diperbolehkan 100cc sampai dengan 2 jam sebelum operasi. Persiapan operasi pasien dilakukan pemasangan kateter vena dengan menggunakan cairan infus $\mathrm{NaCl}$ 0,9\% 12 tetes/menit. Induksi menggunakan obat intravena thiopental $5 \mathrm{mg} / \mathrm{kgBB}$, fentanil $2 \mu \mathrm{g} / \mathrm{kgBB}$, rocuronium $1 \mathrm{mg} / \mathrm{kgBB}$, lidocain $1,5 \mathrm{mg} / \mathrm{kgBB}$, disertai dengan pemberian obat anestetika inhalasi sevofluran 2 vol $\%$ dan $\mathrm{O}_{2} 100 \%$ $6 \mathrm{~L} /$ menit. Setelah dipastikan seluruh obat induksi sudah tercapai onsetnya, dilakukan tindakan intubasi endotrakeal dengan menggunakan ETT no 6.5. Setelah itu, dilakukan pemasangan arterial line pada arteri radialis kanan. Rumatan anestesi diberikan $\mathrm{FiO}_{2} \quad 60 \%$ dengan perbandingan flow oksigen dan udara 2:2, sevofluran 1 vol\%, propofol kontinu $100 \mu \mathrm{g} / \mathrm{kgBB} / \mathrm{min}$, dan fentanil kontinyus $1 \mu \mathrm{g} / \mathrm{kgBB} / \mathrm{jam}$.

Reseksi tumor berlangsung selama 13 jam dengan posisi pasien prone (Gambar 2), dengan jumlah perdarahan sekitar $1800 \mathrm{ml}$. Hemodinamik selama operasi relatif stabil, dengan tekanan darah sistolik berkisar $85-110 \mathrm{mmHg}$, tekanan darah diastolik 50-70 mmHg, laju nadi (HR) 60-80 x/ menit, saturasi oksigen $99-100 \%$, ETCO $30-35$ $\mathrm{mmHg}$, dan suhu $35,5-36,5^{\circ} \mathrm{C}$.(Grafik 1). Selama operasi, hal-hal penting yang diperhatikan adalah
60-80 x/menit, dan saturasi oksigen $98-100 \%$. Pasien masih tersedasi dengan menggunakan propofol $25 \mu \mathrm{g} / \mathrm{kgBB} /$ menit, analgetik fentanil $0,5 \mu \mathrm{g} / \mathrm{kgBB} / \mathrm{jam}$ dan parasetamol $3 \mathrm{x} 1$ gram per hari. Rumatan cairan menggunakan $\mathrm{NaCl}$ $0,9 \% 12$ tetes/menit dan terpasang NGT. Terapi yang diberikan deksametason $3 \times 5 \mathrm{mg}$, ranitidin

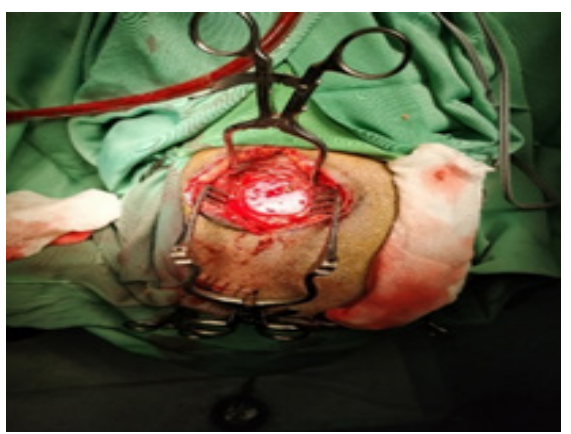

Gambar 2. Posisi Pasien Prone

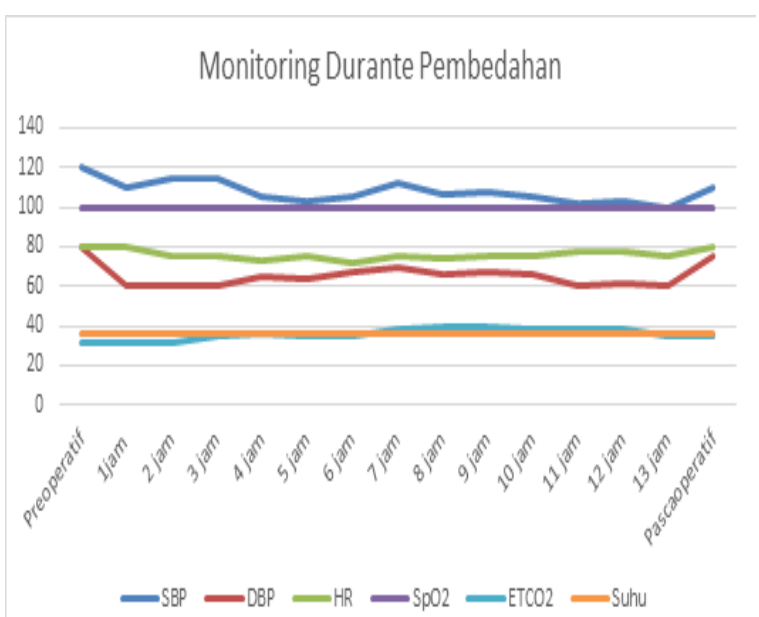

Grafik 1. Hemodinamik periode pre-operasi, induksi, intra-operasi dan pasca operasi

gangguan fungsi saraf kranial, peningkatan tekanan intrakranial, posisi selama operasi, risiko VAE, kehilangan darah dan hipotermi. (Tabel 1)

\section{Pengelolaan Pascabedah}

Pasien dipindahkan ke ruang perawatan intensif, dengan kesadaran masih dalam pengaruh obat, jalan nafas masih terpasang ETT, pernafasan menggunakan ventilator SIMV PS; PEEP 5, PS 7, frekuensi $12 \mathrm{x} /$ menit, $\mathrm{FiO}_{2} 50 \%$. Untuktanda-tanda vital pasien, didapatkan tekanan darah sistolik $110-120 \mathrm{mmHg}$, diastolik $60-80 \mathrm{mmHg}$, nadi 
Tabel 1. Penyulit pada CPA tumor ${ }^{6-9}$

\begin{tabular}{ll}
\hline Penyulit & Ya/Tidak \\
\hline Gangguan Fungsi Saraf Kranial & Ya \\
Peningkatan Tekanan Intrakra- & Ya \\
nial & \\
Posisi Selama Operasi & Prone \\
Risiko VAE & Ya \\
Risiko Kehilangan Darah & Ya \\
Risiko Hipotermia & Ya \\
Monitoring SSP Intraoperatif & Tidak ada \\
\hline
\end{tabular}

$2 \times 50 \mathrm{mg}$, asam traneksamat $3 \times 500 \mathrm{mg}$ iv. Pada hari ke-2 di ruang perawatan intensif, sedasi dihentikan dan dilakukan penurunan kebutuhan ventilator secara bertahap. Pada hari ke-3, pasien dilakukan ekstubasi dan kondisi hemodinamik relatif stabil.

\section{Pembahasan}

Tindakan bedah pada fossa posterior sangat berbahaya dan memerlukan waktu yang lama. Penatalaksanaan anestesi pada kasus tersebut pun sangat menantang, dikarenakan adanya beberapa perhatian khusus seperti ancaman terjadinya disfungsi batang otak, posisi pasien, monitoring neurofisiologis intraoperatif, dan risiko terjadinya emboli udara pada pembuluh darah vena. Pada laporan kasus ini, telah dilakukan operasi pengangkatan tumor dengan diagnosa cerebellopontin angle tumor suspek acoustic schwannoma pada seorang pasien perempuan usia 16 tahun dengan durasi selama 13 jam serta resiko terjadi hipotermia dan ketidakseimbangan cairan selama operasi. Berdasarkan epidemiologi, kasus tumor pada fossa posterior lebih sering terjadi pada anak-anak, dengan insidensi lebih banyak ditemukan pada perempuan dibandingkan laki-laki. Risiko, komplikasi serta durasi operasi ditentukan oleh letak, ukuran tumor dan keahlian dokter bedah, serta monitoring yang baik selama durante operasi. ${ }^{2,6}$

Akses bedah pada daerah fossa posterior dapat diperoleh melalui beberapa posisi bedah yang diterapkan pada pasien. Posisi pasien yang adekuat akan memberikan akses yang memadai terhadap lesi intrakranial. Adapun, beberapa posisi yang dapat diterapkan yaitu posisi lateral, posisi prone, posisi semi telungkup (park bench), posisi duduk, dan posisi supinasi. Posisi pronasi sering digunakan pada anak-anak karena mudah untuk diterapkan dan risiko kejadian VAE yang lebih rendah, tetapi masalah lain yang dapat muncul seperti gangguan ventilasi dengan kontrol jalan nafas yang sulit; edema dan bendungan pembuluh vena pada area wajah; dan penurunan penglihatan karena penggunaan bantal kepala di wajah. ${ }^{6-8}$ Pada kasus ini, tidak didapatkan masalah pada jalan napas selama operasi. Selain itu, pada kasus ini tidak digunakan gas $\mathrm{N}_{2} \mathrm{O}$, dikarenakan adanya efek merusak sel-sel otak dan oksigen diberikan dalam bentuk campuran dengan udara terkompresi sehingga tidak dalam bentuk oksigen murni 100\%. Pemberian oksigen $100 \%$ dalam waktu yang lama tidak dianjurkan karena dapat mengurangi tekanan udara di alveoli, sehingga mudah terjadi atelektasis paru dan vasokonstriksi pada pembuluh darah otak. Secara umum, belum ditemukan pilihan teknik anestesi dan obat-obatan anestesi khusus yang terbaik pada penatalaksanaan kasus tumor fossa posterior. Menurut hasil studi yang ada, tidak disarankan penggunaan gas $\mathrm{N}_{2} \mathrm{O}$ dikarenakan resiko VAE yang lebih tinggi serta gangguan fungsi jantung. Pada kasus ini penggunaan gas inhalasi dikurangi dengan menambahkan obat-obatan intravena kontinu, bertujuan untuk mengurangi efek peningkatan tekanan intrakranial akibat gas inhalasi., ${ }^{9} 10$ Kejadian VAE dapat terjadi dalam jumlah dan durasi yang bervariasi sehingga dapat mengakibatkan perubahan hemodinamik yang cepat seperti peningkatan tekanan jantung kanan, peningkatan dead-space ventilation, dan hipoksemia yang menyebabkan curah jantung akan menurun sebagai akibat dari kegagalan fungsi jantung kanan dan berkurangnya pengisian ventrikel kiri. Peningkatan deadspace ventilation mengakibatkan penurunan tekanan end-tidal carbon dioxide $\left(\mathrm{ETCO}_{2}\right)$, dan peningkatan tekanan arterial karbondioksida. Kedua hal tersebut merupakan gambaran khas pada VAE. Hipoksemia dapat terjadi akibat penyumbatan parsial pembuluh darah pulmonal. VAE dapat dimonitor dengan beberapa metode 
yaitu pemantauan kondisi hemodinamik (tekanan darah, tekanan vena sentral (CVP), tekanan arteri pulmonal), precordial doppler ultrasound, end tidal gas monitoring, transesophageal echocardiography (TEE) dan untuk kasus-kasus risiko tinggi disarankan menggunakan Doppler atau $\mathrm{ETCO}_{2}$. Pada pasien ini kejadian VAE dimonitor dengan menggunakan $\mathrm{ETCO}_{2}$, saturasi oksigen dan IABP. Terdapat beberapa pendapat yang mengatakan dapat mencegah terjadinya VAE, yaitu dengan menggunakan positive endexpiratory pressure (PEEP), pemberian cairan, tindakan hipoventilasi, ataupun modifikasi posisi pasien. Namun, secara pasti PEEP dapat menurunkan aliran balik vena, curah jantung, dan tekanan arteri rata-rata. Pengisian cairan sebagai tindakan profilaksis belum terbukti secara adekuat mengurangi risiko terjadinya VAE meskipun hipovolemi merupakan salah satu faktor predisposisi terjadinya VAE. ${ }^{8,11-13}$

Pada operasi lama, lebih sering terjadi risiko terjadinyagangguanhemodinamik danhipotermia. Kejadian hipotermia itu sendiri terjadi sebagai akibat dari berkurangnya ketersediaan oksigen di tingkat jaringan yang menyebabkan disfungsi trombosit melalui hambatan terhadap pusat pengatur suhu sehingga menghambat beberapa enzim yang terlibat dalam jalur intrinsik dan ekstrinsik dari kaskade koagulasi, dan menyebabkan pemanjangan protrombin dan parsial tromboplastin pada level kaskade koagulasi (ekstrinsik). ${ }^{3,4}$ Pada pasien ini pencegahan terjadinya hipotermia dilakukan dengan menyambungkan cairan infus dengan mesin penghangat, dan risiko gangguan hemodinamik pada pasien ini dicegah dengan pemantauan tekanan darah yang rutin melalui tekanan darah pembuluh arteri (IABP). Selama operasi, pemantauan batang otak umumnya dilakukan karena trauma pada saraf kranial yang merupakan risiko utama operasi di daerah cerebellopontine batang otak. Kondisi saraf kranial dinilai dengan menstimulasi saraf kranial intraoperatif N.V, VII, VIII, XI, XI, XII dengan melakukan SSEP, BAER, dan spontan dan membangkitkan elektromiograf (EMG).

Dalam hal ini pemantauan saraf kranial tidak dilakukan karena alat pemantauan saraf kranial tidak tersedia. Pembedahan di dalam atau di dekat batang otak (misalnya neuroma akustik) dapat mengakibatkan peningkatan respons kardiovaskular yang dapat membahayakan batang otak. Stimulus pada ventrikel IV, N.V dapat menyebabkan hipertensi dan bradikardia. ${ }^{14,15} \mathrm{Pada}$ pasien ini tidak ada perubahan signifikan dalam irama jantung atau perubahan tekanan darah melalui pantauan tekanan darah pembuluh arteri. Pengakhiran anestesi sama dengan bedah saraf lainnya. Penghentian anestesi harus dilakukan dengan hati-hati, lancar, hindari batuk, dan hindari peningkatan tekanan darah secara tibatiba. Ekstubasi dilakukan tergantung pada beberapa faktor seperti kondisi gangguan neurologis yang sebelumnya terjadi, durasi operasi, komplikasi intraoperatif dan edema batang otak. Dalam hal ini pasien tidak segera terbangun, pasien masih dibius dan menggunakan ETT setelah operasi selesai sampai hari ke-3.

Hal ini dikarenakan pada hari ke-1 pasien baru menjalani operasi yang lama dengan risiko gangguan hemodinamik dan pada hari ke-2 pasien masih mendapatkan terapi steroid untuk mengurangi terjadinya edema cerebri. Setelah hari ke-3 pasien dilakukan ekstubasi setelah dipastikan adanya reflek batuk yang adekuat, kesadaran baik, dan hemodinamik stabil. Selama perawatan, pasien juga mendapat analgesik yang memadai dengan menggunakan fentanyl untuk mencegah pasien kesakitan dan peningkatan tekanan darah dan denyut nadi.

\section{Simpulan}

Operasi yang memanjang pada kasus CPA menghadirkan tantangan signifikan bagi ahli anestesi karena risiko hipotermi, gangguan hemodinamik, dan cedera pada saraf kranial yang dapat terjadi pada pasien ini. Risikorisiko ini dapat dihindari dengan mengambil tindakan pencegahan yaitu dengan pemberian infus penghangat dan blower, pengulangan pemeriksaan analisa gas darah, pemeriksaan gula darah berkala serta pemasangan arterial line untuk pemantauan pasien selama operasi. 


\section{Daftar Pustaka}

1. Yang D, Zhao Y, Song L, Guo F. A rare case of pediatric cerebellopontin angle meningoma presenting seizure. Life Science Journal. 2013;10(3): 1307-09.

2. Moosa S, Ding D. Role of stereotactic radiosurgery in the management of Cerebellopontine angle tumors. Austin J Radiat. Oncol \& Cancer. 2015;1(1):1004.

3. Rivera-Flores J. Evaluación primaria del paciente traumatizado. Rev Mex Anest. 2012;35:136-39.

4. Etxaniz A, Pita E. Management of bleeding and coagulopathy following major trauma. Rev Esp Anestesiol Reanim 2016;63:289-96.

5. Chand MB, Thapa P, Shrestha S, Chand P. Peri-operative anesthetic events in posterior fossa tumor surgery. Postgraduate Medical Journal of NAMS. 2012;12(2).

6. Schlichter RA, Smith DS. Anesthetic management for posterior fossa surgery. Dalam: Cottrell JE, Patel P, eds. Neuroanesthesia, Edisi ke-6, Elsevier, Inc; 2017;225-35.

7. Pederson DS, Peterfreund RA. Anesthesia for posterior fossa surgery. Dalam: Newfield P, CottrellJE, eds. Handbook of Neuroanesthesia 5th ed. Philadelphia; Lippincott Williams \& Wilkins; 2012;136-47.

8. Jagannathan S, Krovvidi H. Anaesthetic considerations for posterior fossa surgery.
Continuing Education in Anaesthesia, Critical Care \& Pain. 2014;14(5):202-06.

9. Patel, Wen DY, Haines SJ. Posterior fossa: surgical consideration. Dalam: Cottrell JE, Smith DS, eds. Anesthesia and Neurosurgery, Edisi ke-4, Missouri: Mosby, Inc; 2001;31933.

10. Sinead SS, Ma D. The neurotoxicity of nitrous oxide: the facts and "putative" mechanisms. Brain Sci. 2014;4:73-90.

11. Mirski MA, Lele AV, Fitzsimmons L, Toung TJ. Diagnosis and treatment of vascular air embolism. Anesthesiology. 2007;106:16477.

12. Gheorghita E, Ciurea J, Balanescu B. Considerations on anesthesia for posterior fossa-surgery. Romanian Neurosurgery. 2012;19(3):183-92.

13. Abd-Elsayed AA, Díaz-Gómez J, Barnett $\mathrm{GH}$, Kurz A, Inton-Santos M, Barsoum S, et al. A case series discussing the anaesthetic management of pregnant patients with brain tumours. F1000Research. 2013;2:92.

14. Goyal K, Philip FA, Rath GP, Mahajan C, Sujatha M, Bharti SJ, dkk. Asystole during posterior fossa surgery: report of two cases. Asian J Neurosurg. 2012;7(2):87-9.

15. Betka J, Zvěřina E, Balogová Z, Profant $O$, Kraus J, dkk. Complications of microsurgery of vestibular schwannoma. BioMed Research International 2014;1-10. 